\title{
The impact of variation in iodine food composition data on the estimates of iodine intake in Irish 2 year olds
}

\author{
Á Hennessy ${ }^{1}$, C ní Chaoimh ${ }^{1,2}$, E.K. McCarthy ${ }^{1,2}$, C Kingston $^{1}$ and M. Kiely ${ }^{1,2}$ \\ ${ }^{1}$ Cork Centre for Vitamin D and Nutrition Research, School of Food and Nutritional Sciences and ${ }^{2}$ The Irish Centre \\ for Fetal and Neonatal Translational Research, University College Cork
}

Iodine, an essential component of thyroid hormone, plays an important role in neurodevelopment. The reliability of an estimate of iodine intake is largely dependent on quality of the food composition data in terms of completeness, currency and the extent to which natural variability in iodine content is taken into account. Milk is a significant source of iodine and the iodine content of milk is highly variable due to the use of animal feeds during the winter period and iodine-containing teat disinfectants pre- and post-milking ${ }^{(1)}$.

The aim of this study was to assess the impact of using 2 different sources of iodine composition data on the estimates of iodine intake, adequacy and potential for excessive intakes in 2 year old children participating in the Cork BASELINE Birth Cohort Study. A total of 468 2-day weighed food records were collected and dietary intake data were extracted and analysed using (i) UK food composition data ${ }^{(2)}$ and (ii) analytical values for Irish foods obtained from the Food Safety Authority of Ireland (FSAI) Total Diet Study $(2012-2014)^{(3)}$. A total of 690 food items (including composite dishes) were adjusted using the FSAI analytical iodine composition values ( $n$ 141), representing $56 \%$ of all food items consumed. Mean daily iodine intakes were calculated using both UK and FSAI analytical data and values were compared with selected dietary reference values (DRVs) ${ }^{(4,5)}$.

We found that daily iodine intake in Irish 2 year olds was adequate. Daily estimates of iodine intake derived using UK and Irish composition values were significantly different $(P<0.001)$, with a mean (SD) difference of $30(34) \mu \mathrm{g} / \mathrm{d}$, representing $75 \%$ of the UK LRNI, and $43 \%$ of the UK RNI. The key dietary sources of iodine were milk (UK: $58 \%$, FSAI: $69 \%$ ), yoghurt (UK: $9 \%$, FSAI: $6 \%$ ), formula (UK: $6 \%$; FSAI: $5 \%$ ) and fish (UK: $5 \%$, FSAI: $3 \%$ ). Though small but significant differences in the estimates of iodine intake below selected DRVs were observed, the estimates of intakes exceeding the tolerable upper intake level (UL) were substantially different (UK: $22 \%$, FSAI: $35 \%$ ). UK and FSAI P95 intakes were $138 \%$ and $173 \%$ of the UL, respectively, of which milk intake accounted for $106 \%$ and $150 \%$ of UL.

\begin{tabular}{|c|c|c|c|c|}
\hline \multicolumn{5}{|c|}{ Mean (SD) estimates of daily iodine intake in Irish 2 year olds in the Cork BASELINE Birth Cohort Study (n 468) using UK and Irish analytical composition values } \\
\hline Iodine intake $(\mu \mathrm{g} / \mathrm{d})$ & Mean & SD & Median & IQR \\
\hline$\overline{U K}$ & 147.2 & 71.0 & 131.8 & $96 \cdot 7$ \\
\hline \multirow[t]{2}{*}{$F S A I$} & $177 \cdot 2^{*}$ & $92 \cdot 9$ & 158.9 & $127 \cdot 6$ \\
\hline & $\%<$ LRNI $^{(4)}$ & $\%<\mathbf{R N I}^{(4)}$ & $\%>$ EFSA UL ${ }^{(5)}$ & P95 as $\%$ of $\mathrm{UL}^{(5)}$ \\
\hline$U K$ & 0.7 & $8 \cdot 3$ & $21 \cdot 8$ & 137.6 \\
\hline$F S A I$ & 0.7 & $7 \cdot 3^{*}$ & $34.8^{*}$ & 173.3 \\
\hline
\end{tabular}

*denotes significant difference between UK and FSAI (Irish) estimates $(P<0 \cdot 05)$ (Paired Samples T-test \& McNemar's test)

The variability in the iodine content of dairy foods in particular results in the greatest disparity between estimates of intake, particularly at the higher end of the intake distribution. Accurate and up-to-date composition data, which account for seasonal variation and agricultural practices, are essential for reliable estimation of iodine intake. Though the risk of adverse effects is low ${ }^{(5,6)}$, the findings of this study indicate that careful consideration of high iodine intakes in young children as a consequence of high milk consumption is required.

1. O'Brien B, Gleeson D, Jordan K (2013) Irish J Ag Food Res 52, 209-216.

2. Finglas P, Roe M, Pinchen H, et al. (2015). Cambridge: The Royal Society of Chemistry.

3. Food Safety Authority of Ireland (2016) Dublin: FSAI.

4. Department of Health (1991) London: H.M.S.O.

5. Scientific Committee on Food (2002) Brussels: EFSA

6. UK Expert Group on Vitamins and Minerals (2003) Great Britain: Food Standards Agency. 